\title{
Analyzing Features and Social Determinants of the Incidence of Class A and B Notifiable Infectious Diseases in China From 2004 to 2018
}

\section{Chenxi Zhang}

Weifang Medical University

Haiyin Wang

Shanghai Health Development Research Center

Chunlin Jin ( $\nabla$ jinchunlin@shdrc.org)

Shanghai Health Development Research Center

\section{Research Article}

Keywords: features of incidence, infectious diseases, social determinants

Posted Date: June 25th, 2021

DOI: https://doi.org/10.21203/rs.3.rs-634568/v1

License: (c) (i) This work is licensed under a Creative Commons Attribution 4.0 International License.

Read Full License 


\section{Abstract}

Background: The social order of the whole world has been disrupted since the COVID-19 outbreak. In China, we added novel coronavirus pneumonia to the list of Class B notifiable infectious diseases, and we placed Class A notifiable infectious diseases under strict monitoring. Therefore, it is significant that we study the features and social determinants of the incidence of both Class A and B infectious diseases.

Methods: We analyzed the annual percentage change in the incidence of overall infectious diseases and the four main diseases by descriptive statistics analysis, estimated the differences in the incidence of infections in seven regions over 15 years by using a generalized estimation equation (GEE), and then determined social determinants affecting these infectious diseases by using a panel data model.

Results: The incidence of overall Class A and B infectious diseases has been declining since January 2004. The infectious diseases with the highest yearly incidence were hepatitis, tuberculosis, syphilis, and bacterial and amoebic dysentery, with an incidence rate that has remained stable over the past 15 years. The locations of disease incidence in ascending order from low to high was East China, Northeast China, North China, Southwest China, Central China, South China, and Northwest China $\left(c^{2}=68.60 p<0.001\right)$. The changes in the characteristics of yearly incidence varied $\left(c^{2}=44.84 p<0.001\right)$. We found that two determinants, namely, percentage of people with illiteracy in the total population aged 15 years and older $(p=0.01)$ and number of family health service people per capita $(p<0.001)$, were positive for infectious diseases. Three determinants, including public green areas per capita $(p<0.001)$, number of public transportation vehicles per 10000 people $(p=0.02)$ and area of paved roads per capita $(p<0.001)$, were negative for infectious diseases.

Conclusions: We successfully prevented and controlled Class A and B infectious diseases after the outbreak of severe acute respiratory syndrome (SARS) in 2003. Over the years, hepatitis and tuberculosis have had the highest incidence among infectious diseases and thus more attention needs to be given to these diseases. Social determinants had a significant influence on infectious diseases. Some strategies related to social determinants are needed to prevent infectious diseases.

\section{Introduction}

As of 16 April 2021, 137866311 cases of COVID-19 were reported, including 2965707 deaths [1]. Societies and economies have been damaged, and disparities have widened between nations because of this epidemic [2]. Infectious diseases will be at the top of the list of highest impact risks to the world in the following decades [3]. This attention implies that the outbreak of emerging infectious diseases will exert critical and negative influences with strong impacts to some countries or regions, especially underdeveloped countries.

On 20th January 2020, the National Health Commission of the People's Republic China (NHC) classified novel coronavirus pneumonia as a Class B infectious disease under the Law of the People's Republic of China on Prevention and Treatment of Infectious Diseases and took prevention and control measures for 
Class A infectious diseases [4]. The infectious diseases governed by this law were categorized into Classes A, B and C through a supervisory control system that the government has been building for decades and completed [5], and these classifications includes 2 Class A infectious diseases, namely, plague and cholera; 25 Class B infectious diseases, such as SARS and AIDS; and 10 Class C infectious diseases, such as influenza [6]. Although we successfully controlled Class A infectious diseases, we continue to pay attention to routinely preventing and controlling them because they spread quickly and have the highest mortality. Class B infectious diseases were the focus of daily prevention and control because they each have a higher incidence and are thus more harmful to the population [7]. The incidence of infectious diseases is not only related to the source of infection, route of transmission and susceptible population; it is also affected by social determinants [8]. Hence, we determined the discipline related to and deep-rooted causes of the features and social determinants of the incidence of Class $A$ and $B$ notifiable infectious diseases in different provinces or regions. We also identified the regions and procedures that show weak effects in the prevention and control of infectious diseases. Eventually, we will provide scientific evidence to improve infectious disease prevention and control and achieve the strategic goal of Healthy China 2030.

\section{Methods}

\section{Definition of the incidence of infectious diseases and social determinants}

We defined the incidence (per 100000 people) of infectious diseases as the number of annual new incident cases divided by the annual population size. Some factors, including social, economic, political, and environmental factors [9], which contribute directly to health and disease, are defined as social determinants of health [10]. We sorted the factors into four aspects, namely, social factors, economic factors, demographic factors and hygiene factors, in this research. We chose the index of this research according to a previous study conducted in China [11].

\section{Study population and design}

This study involved all populations who became infected with infectious diseases in mainland China. We accessed 15 years (from 2004 to 2018) of data on the incidence of Class A and B notifiable infectious diseases in the whole nation and each of the 31 provinces. To examine the significant differences between the levels of incidence, we sorted 465 incidences of infectious diseases in the 31 provinces over 15 years into four groups: the first group had a minimum incidence of less than 150 cases per 100000 people; the second group had a lower incidence, of 151 to 300 cases per 100000 people; the third group had a higher incidence from 301 to 450 cases per 100000 people; and the fourth group had a maximum incidence of more than 450 cases per 100000 people. We also examined the significant differences between different regions of China, sorting 31 provinces in mainland China into seven regions according to geographic location: North China (Beijing, Tianjin, Hebei, Shanxi_e, and Neimenggu), Northeast China (Liaoning, Jilin, and Heilongjiang), East China (Shanghai, Jiangsu, Zhejiang, Anhui, Fujian, Jiangxi, and 
Shandong), Central China (Henan, Hubei, and Hunan), South China (Guangdong, Guangxi, and Hainan), Southwest China (Chongqing, Sichuan, Guizhou, Yunnan, and Tibet), and Northwest China (Shanxi_W, Gansu, Qinghai, Ningxia, and Xinjiang).

When we analyzed the social determinants of the incidence of infectious diseases with panel data, the incidence was the dependent variable, and social factors, economic factors, demographic factors and hygiene factors were the independent variables (Table 3 ). These variables were based on yearly data obtained for 15 years for every province in mainland China.

\section{Data extraction}

Incidence data for overall Class A and B notifiable infectious diseases and each of the four main infectious diseases were extracted from the China Health Statistics Yearbook for the years from 2005 to 2019. Social determinant data were extracted from the China Statistics Yearbook for the years from 2005 to 2019. Both yearbooks included data from 31 provinces in mainland China.

\section{Statistical analysis}

We described the annual percentage change in the incidence of overall infectious diseases, and each of the four main diseases was assessed using Excel. We estimated differences among seven regions and over 15 years by GEE using IBM SPSS Modeler (version 15.0). Social determinants affecting these infectious diseases were identified with a panel data model using STATA 15. This study included a short and balanced panel covering 15 years, from 2004-2018, and 31 provinces $(n>T)$.

\section{The procedure used to choose two-way FE as the final model}

Step 1: The choice between the pooled regression model (PLS) and unobserved effects model, including the fixed effects model (FE) and random effects model (RE) [12]

PLS or FE? We chose between a PLS or FE on the basis of Frees test ( $a=0.05$, critical value $=0.22$ ) according to the characteristics of the data obtained for this study, which were balanced panels showing time effects. The result of this test showed that there was a sectional correlation in the error term (3.94 > 0.22 ) in the FE; therefore, we chose the FE with individual-specific effects, instead of the PLS, using a joint hypotheses test $\left(F_{(14,14)}=4071.41, p<0.001\right)$.

PLS or RE? We chose between a PLS or RE on the basis of Lagrangian multiplier test (LM test) $(a=0.05)$ [13]. The results of this test showed that we should choose the RE with individual-specific effects $(p<0.001)$, not the PLS.

Step 2: FE or RE?

We chose an FE or RE on the basis of Frees test ( $a=0.05$ [13], critical value $=0.22$ ). According to the results of this test, there was a sectional correlation in the error term $(3.89>0.22)$ in the RE, and therefore, 
we chose the FE by Hausman test $3\left(F_{(14,14)}=2694.91, p<0.001\right)$, not the RE.

Therefore, we analyzed the data using a two-way fixed effects model (two-way FE). In formula (1), $i=1, \ldots$ $n, t=1, \ldots, T, x_{i t}$ is an independent variable, $\lambda_{t}$ is a time effect that is an individual invariant, $a_{i}$ is an individual-specific effect that is time invariant, and $\varepsilon_{i t}$ is an error term that varies by time and individual.

$$
Y_{i t}=\beta x_{i t}+\lambda_{t}+\alpha_{i}+\varepsilon_{i t}
$$

\section{Results}

\section{Features of the incidence of infectious diseases from 2004 to 2018}

Between January 2004 and December 2018, a total of 48690800 cases of Class A and B infectious diseases and 27 infectious diseases were reported, resulting in an average incidence of 241.43 cases per 100000 people per year. The infectious diseases with the highest yearly incidence were hepatitis (194.92 cases per 100000 people), tuberculosis ( 148.16 cases per 100000 people), syphilis (60.58 cases per 100 000 people), and bacterial and amoebic dysentery (46.32 cases per 100000 people), which together accounted for $92.4 \%$ (223.11 of 241.43 cases) of overall incidence.

The overall incidence of infectious diseases has been declining since 2004 (Figure 1), with the two largest variations from 2004 to 2005 (23.65 cases per 100000 people) and from 2009 to 2010 (-24.83 cases per 100000 people). The trend of the incidence of hepatitis was more stable, with the two largest variations from 2005 to 2006 (10.7 per 100000 people) and from 2012 to 2013 (-10 cases per 100000 people). The incidence of tuberculosis had declined since 2005, with the largest variation from 2004 to 2005 (21.7 cases per 100000 people). The incidence of syphilis had been increasing, and the incidence of bacterial and amoebic dysentery had been decreasing. In general, the variation in the incidence of all four main infectious diseases became stable throughout these years (Figure 2).

\section{Analysis of differences in the incidence of infectious diseases in seven regions}

Table 1 shows the results of the GEE; there was a statistically significant difference between the seven regions $\left(c^{2}=68.60 p<0.001\right)$, with a higher incidence in Northwest China. The incidence in North, Northeast, East, Central, and Southwest China was $4.6 \%, 2 \%, 1.4 \%, 8 \%$, and $7.8 \%$, respectively, that in Northwest China. In summary, the order of incidence from low to high was East China, Northeast China, North China, Southwest China, Central China, South China, and Northwest China. There was a statistically significant difference over the 15 years $\left(c^{2}=44.84 p<0.001\right)$. The incidence of infectious diseases was 4.9 fold, 6.8-fold, 7.7-fold, and 6.7-fold higher from 2005 to 2009, respectively, than it was in 2018; however, there was no statistically significant difference between the years from 2010 to 2017 and 2018 . Table 2 
indicates that the GEE results were reliable because the prediction accuracy of the model was $(266+39) / 465=65.6 \%$, which is more than $60 \%$.

\section{Table 1: GEE results}




\begin{tabular}{|c|c|c|c|c|}
\hline & & $\beta$ & OR $(95 \% C l)$ & $p$ \\
\hline \multirow{3}{*}{ threshold } & incidence $=1$ & -5.12 & & $\nabla 0.001 * \star \star$ \\
\hline & incidence $=2$ & -0.31 & & 0.737 \\
\hline & incidence $=3$ & 2.31 & & $0.034^{\star}$ \\
\hline \multirow{7}{*}{ regions } & North China & -3.08 & $0.046(0.005 \sim 0.414)$ & $0.006^{\star \star}$ \\
\hline & Northeast China & -3.94 & $0.02(0.003 \sim 0.117)$ & $\nabla 0.001 * \star \star$ \\
\hline & East China & -4.28 & $0.014(0.002 \sim 0.126)$ & $\nabla 0.001 * \star \star$ \\
\hline & Central China & -2.53 & $0.08(0.011 \sim 0.558)$ & $0.011^{*}$ \\
\hline & South China & -0.69 & $0.502(0.095 \sim 2.667)$ & 0.419 \\
\hline & Southwest China & -2.56 & $0.078(0.014 \sim 0.416)$ & $0.003^{\star \star}$ \\
\hline & Northwest China & 0 & 1 & \\
\hline \multirow{15}{*}{ time/year } & 2004 & 1.34 & $3.816(0.924 \sim 15.755)$ & 0.064 \\
\hline & 2005 & 1.60 & 4.933(1.402 17.361) & $0.013^{\star}$ \\
\hline & 2006 & 1.91 & $6.757(1.68 \sim 27.178)$ & $0.007 * \star$ \\
\hline & 2007 & 2.01 & 7.461(2.09 26.639) & $0.002^{\star \star}$ \\
\hline & 2008 & 2.04 & 7.692(2.02 29.282) & $0.003^{\star \star}$ \\
\hline & 2009 & 1.90 & 6.698(1.776 25.254) & $0.005^{\star \star}$ \\
\hline & 2010 & 0.57 & $1.764(0.671 \sim 4.639)$ & 0.250 \\
\hline & 2011 & 0.61 & $1.836(0.674 \sim 5.002)$ & 0.235 \\
\hline & 2012 & 0.74 & $2.096(0.733 \sim 5.996)$ & 0.168 \\
\hline & 2013 & 0.10 & $1.106(0.575 \sim 2.126)$ & 0.762 \\
\hline & 2014 & 0.15 & $1.161(0.58 \sim 2.323)$ & 0.674 \\
\hline & 2015 & 0.16 & $1.167(0.669 \sim 2.038)$ & 0.586 \\
\hline & 2016 & -0.31 & $0.734(0.501 \sim 1.077)$ & 0.114 \\
\hline & 2017 & -0.07 & $0.932(0.655 \sim 1.326)$ & 0.697 \\
\hline & 2018 & 0 & 1 & \\
\hline \multicolumn{2}{|l|}{ 『Scale》 } & 1 & & \\
\hline \multicolumn{4}{|c|}{ time $c^{2}=44.84 p<0.001^{\star \star \star}$} & \\
\hline
\end{tabular}


* $p<0.05^{* *} p<0.01 * * * p<0.001$

tWe sorted all incidences of the infectious diseases from 31 provinces into four groups. The first result, incidence $=1$, indicates the gap from the first group with the minimum incidence to the second group with the lower incidence. The second result, incidence=2, indicates the gap from the second group to the third group with the higher incidence. The third result, incidence=3, indicates the gap from the third group to the fourth group with the maximum incidence.

Table 2: Prediction accuracy

\begin{tabular}{|lllll|}
\hline & & \multicolumn{2}{c}{ Predicted Value } & \multirow{2}{*}{ Total } \\
\cline { 1 - 4 } incidence & & $150-300$ & $300-450$ & \\
(per 100 000 people) $)$ & $0-150$ & 37 & 0 & 37 \\
\cline { 2 - 5 } & $150-300$ & 266 & 33 & 299 \\
\cline { 2 - 5 } & $300-450$ & 64 & 39 & 103 \\
\cline { 2 - 5 } Total & $450-750$ & 1 & 25 & 26 \\
\hline
\end{tabular}

\section{Analysis of the social determinants of the incidence of infectious diseases}

Panel data have some advantages, such as overcoming endogeneity caused by unobserved heterogeneity and improved accuracy of the estimation. We deflated GDP per capita by the price index, with the price in 2004 kept the same. Table 3 shows the variable assignments and the descriptive statistics for the dependent and independent variables.

Table 3: Descriptive statistics for the dependent and independent variables 


\begin{tabular}{|c|c|c|c|c|c|c|}
\hline Variables & Name (Unit) & Obs & Mean & SD & Min & Max \\
\hline Y & $\begin{array}{l}\text { incidence of infectious diseases (per } 100 \\
000 \text { people) }\end{array}$ & 465 & 266.13 & 100.8 & 102.48 & 738.19 \\
\hline $\mathrm{X}_{1}$ & GDP per capita (10 000 yuan) & 465 & 12.45 & 11.79 & 0.48 & 70.91 \\
\hline $\mathrm{x}_{2}$ & $\begin{array}{l}\text { passenger traffic on highways ( } 100 \\
\text { million persons) }\end{array}$ & 465 & 6.95 & 6.95 & 0.03 & 55.65 \\
\hline$x_{3}$ & $\begin{array}{l}\text { healthcare expenditure per capita as } \\
\text { percentage of consumption expenditure } \\
\text { per capita (\%) }\end{array}$ & 465 & 6.96 & 1.89 & 2.63 & 13.15 \\
\hline $\mathrm{X}_{4}$ & sex ratio (female=100) & 465 & 1.04 & 0.04 & 0.95 & 1.2 \\
\hline$X_{5}$ & age $0-14$ years $(\%)$ & 465 & 17.27 & 4.32 & 7.56 & 28.34 \\
\hline$x_{6}$ & aged 65 years and older (\%) & 465 & 9.87 & 2.35 & 4.82 & 18.32 \\
\hline$x_{7}$ & $\begin{array}{l}\text { percentage of the illiterate population to } \\
\text { total population of people aged } 15 \text { years } \\
\text { and older }(\%)\end{array}$ & 465 & 7.78 & 7.02 & 1.23 & 45.65 \\
\hline $\mathrm{X}_{8}$ & urban population proportion (\%) & 465 & 52.08 & 14.73 & 21.5 & 89.6 \\
\hline$X_{9}$ & average educational attainment (year) & 465 & 8.59 & 1.23 & 3.74 & 12.56 \\
\hline $\mathrm{X}_{10}$ & $\begin{array}{l}\text { urban population density (sq.km per } \\
1000 \text { people) }\end{array}$ & 465 & 2.6 & 1.31 & 0.19 & 6.31 \\
\hline $\mathrm{X}_{11}$ & public green areas per capita (sq.m) & 465 & 10.81 & 3.27 & 0.42 & 20.38 \\
\hline $\mathrm{X}_{12}$ & $\begin{array}{l}\text { daily consumption of tap water for } \\
\text { residential use per capita (cu.m) }\end{array}$ & 465 & 0.16 & 0.06 & 0.07 & 0.32 \\
\hline $\mathrm{X}_{13}$ & $\begin{array}{l}\text { registered unemployment rate in urban } \\
\text { area }(\%)\end{array}$ & 465 & 3.51 & 0.68 & 1.21 & 6.5 \\
\hline $\mathrm{X}_{14}$ & $\begin{array}{l}\text { coverage rate of urban population with } \\
\text { access to tap water (\%) }\end{array}$ & 465 & 0.95 & 0.07 & 0.49 & 1.23 \\
\hline $\mathrm{X}_{15}$ & $\begin{array}{l}\text { number of public transportation vehicles } \\
\text { per } 10000 \text { people (unit) }\end{array}$ & 465 & 11.45 & 3.68 & 3.99 & 26.55 \\
\hline$x_{16}$ & area of paved roads per capita (sq.m) & 465 & 13.5 & 4.47 & 4.04 & 25.82 \\
\hline$x_{17}$ & $\begin{array}{l}\text { number of grass-roots medical and } \\
\text { health institutions ( } 1000 \text { units) }\end{array}$ & 465 & 22.56 & 20.06 & 1.08 & 82.24 \\
\hline$X_{18}$ & $\begin{array}{l}\text { number of staff in the center for diseases } \\
\text { control and prevention per } 10000 \text { people } \\
\text { (persons) }\end{array}$ & 465 & 1.68 & 0.64 & 0.76 & 3.94 \\
\hline$X_{19}$ & $\begin{array}{l}\text { number of staff of health technicians per } \\
1000 \text { people (persons) }\end{array}$ & 465 & 5.14 & 1.92 & 2 & 15.46 \\
\hline
\end{tabular}




\begin{tabular}{|lllllll|}
\hline $\mathrm{X}_{20}$ & $\begin{array}{l}\text { number of center for diseases control } \\
\text { and prevention (units) }\end{array}$ & 465 & 113.39 & 56.03 & 19 & 229 \\
\hline $\mathrm{X}_{21}$ & $\begin{array}{l}\text { number of family health service people } \\
\text { per capita (100 units) }\end{array}$ & 465 & 1.78 & 1.72 & 0.1 & 22.19 \\
\hline
\end{tabular}

The trends in the incidence of infectious diseases in the 31 provinces are presented in Figure 3. Incidence declined in 14 provinces: Beijing, Tianjin, Hebei, Jilin, Heilongjiang, Shanghai, Jiangsu, Zhejiang, Fujian, Henan, Sichuan, Shanxi_w, Gansu, and Ningxia. It was stable in 6 provinces: Shanxi_e, Neimenggu, Jiangxi, Hubei, Guizhou, and Yunnan. It increased in 4 provinces: Anhui, Shandong, Hunan, and Tibet. In the final year of this study, three provinces had a higher incidence of infectious diseases than the other provinces: Xinjiang (659.75 cases per 100000 people), Qinghai (433.29 cases per 100000 people) and Hannan (360.04 cases per 100000 people). In contrast, three provinces had lower incidence of infectious disease: Jilin (132.50 cases per 100000 people), and Beijing (131.49 cases per 100000 people) and Jiangsu (113.50 cases per 100000 people).

Table 4 shows the three statistical results with different standard errors. We chose the result of two-way FE with Driscoll-Kraay standard error because of heteroscedasticity $\left(c^{2}=1237.50, p \rrbracket 0.001\right)$, autocorrelation $\left(F_{(1,30)}=46.74, p \otimes 0.001\right)$ and sectional correlation in the model.

Table 4: The statistical analysis results with different standard errors 


\begin{tabular}{|c|c|c|c|}
\hline & \multicolumn{3}{|c|}{ dependent variable: $Y$} \\
\hline & $(1)$ & $(2)$ & (3) \\
\hline & Driscoll-Kraay & Rogers & White \\
\hline \multirow[t]{2}{*}{$x_{1}$} & -0.45 & -0.45 & -0.45 \\
\hline & $(0.196)$ & $(0.605)$ & $(0.605)$ \\
\hline \multirow[t]{2}{*}{$x_{2}$} & -0.75 & -0.75 & -0.75 \\
\hline & $(0.116)$ & $(0.391)$ & $(0.391)$ \\
\hline \multirow[t]{2}{*}{$x_{3}$} & -0.66 & -0.66 & -0.66 \\
\hline & $(0.882)$ & $(0.896)$ & $(0.896)$ \\
\hline \multirow[t]{2}{*}{$x_{4}$} & -52.57 & -52.57 & -52.57 \\
\hline & $(0.432)$ & $(0.644)$ & $(0.644)$ \\
\hline \multirow[t]{2}{*}{$x_{5}$} & 0.22 & 0.22 & 0.22 \\
\hline & $(0.922)$ & $(0.97)$ & $(0.97)$ \\
\hline \multirow[t]{2}{*}{$x_{6}$} & -3.56 & -3.56 & -3.56 \\
\hline & $(0.402)$ & $(0.434)$ & $(0.434)$ \\
\hline \multirow[t]{2}{*}{$x_{7}$} & $5.16^{\star \star}$ & 5.16 & 5.16 \\
\hline & $(0.01)$ & $(0.181)$ & $(0.181)$ \\
\hline \multirow[t]{2}{*}{$x_{8}$} & 2.23 & 2.23 & 2.23 \\
\hline & $(0.206)$ & $(0.436)$ & $(0.436)$ \\
\hline \multirow[t]{2}{*}{$X_{9}$} & 4.53 & 4.53 & 4.53 \\
\hline & $(0.623)$ & $(0.671)$ & $(0.671)$ \\
\hline \multirow[t]{2}{*}{$x_{10}$} & 3.96 & 3.96 & 3.96 \\
\hline & $(0.217)$ & $(0.412)$ & $(0.412)$ \\
\hline \multirow[t]{2}{*}{$x_{11}$} & $-8.14 \star \star \star$ & $-8.14^{\star}$ & $-8.14^{\star}$ \\
\hline & $(0)$ & $(0.023)$ & $(0.023)$ \\
\hline \multirow[t]{2}{*}{$X_{12}$} & 50.26 & 50.26 & 50.26 \\
\hline & $(0.684)$ & $(0.845)$ & $(0.845)$ \\
\hline \multirow[t]{2}{*}{$\mathrm{X}_{13}$} & 3.88 & 3.88 & 3.88 \\
\hline & $(0.616)$ & $(0.71)$ & $(0.71)$ \\
\hline
\end{tabular}




\begin{tabular}{|c|c|c|c|}
\hline \multirow[t]{2}{*}{$X_{14}$} & 85.97 & 85.97 & 85.97 \\
\hline & $(0.17)$ & $(0.464)$ & $(0.464)$ \\
\hline \multirow[t]{2}{*}{$\mathrm{X}_{15}$} & $-5.47^{\star}$ & $-5.47 *$ & $-5.47^{\star}$ \\
\hline & $(0.016)$ & $(0.027)$ & $(0.027)$ \\
\hline \multirow[t]{2}{*}{$\mathrm{X}_{16}$} & $6.86^{\star \star \star}$ & $6.86^{\star}$ & $6.86^{\star}$ \\
\hline & $(0)$ & $(0.01)$ & $(0.01)$ \\
\hline \multirow[t]{2}{*}{$\mathrm{X}_{17}$} & 0.76 & 0.76 & 0.76 \\
\hline & $(0.055)$ & $(0.218)$ & $(0.218)$ \\
\hline \multirow[t]{2}{*}{$\mathrm{X}_{18}$} & 7.61 & 7.61 & 7.61 \\
\hline & $(0.735)$ & $(0.781)$ & $(0.781)$ \\
\hline \multirow[t]{2}{*}{$\mathrm{X}_{19}$} & -6.89 & -6.89 & -6.89 \\
\hline & $(0.075)$ & $(0.053)$ & $(0.053)$ \\
\hline \multirow[t]{2}{*}{$x_{20}$} & 0.71 & 0.71 & 0.71 \\
\hline & $(0.109)$ & $(0.223)$ & $(0.223)$ \\
\hline \multirow[t]{2}{*}{$x_{21}$} & $7.90^{* \star *}$ & 7.90 ** & 7.90 ** \\
\hline & $(0)$ & $(0.007)$ & $(0.007)$ \\
\hline$N$ & 465 & 465 & 465 \\
\hline \multicolumn{4}{|c|}{$\star p<0.05, * \star p<0.01, * \star \star p<0.001$} \\
\hline \multicolumn{4}{|c|}{ tWe could use the standard error of Rogers and White when there was no } \\
\hline \multicolumn{4}{|c|}{ sectional correlation in the model. The results with the Driscoll-Kraay } \\
\hline \multicolumn{4}{|c|}{ standard error was supported by the results with those two standard errors, except $X_{7}$. } \\
\hline
\end{tabular}

The results from the two-way FE used in this study was statistically significant $\left(F_{(35,14)}=500.23, p \llbracket 0.001\right.$, $\left.R^{2}=0.40\right)$. Five social determinants of the incidence of Class $A$ and $B$ notifiable infectious diseases were statistically significant (Table 5). At a significance level of $a=0.001$, the factor public green areas per capita increased by 1 unit, causing an 8.14 unit reduction in the incidence of infectious diseases. The factor area of paved roads per capita increased by 1 unit, causing a 6.86 unit increase in the incidence of infectious diseases. The factor number of family health services people per capita increase by 1 unit, causing a 7.9 unit increase in the incidence of infectious diseases. At a significance level of $a=0.01$, the factor percentage of the illiterate population to the total population of people aged 15 years and older increased by 1 unit, causing a 5.16 unit increase of the incidence of infectious diseases. At a significance level of $a=0.05$, the factor number of public transportation vehicles per 10000 people increased by 1 
unit, causing a 5.47 unit reduction in the incidence of infectious diseases. In summary, increases in three social determinants, the proportion of illiterate population to the total population of people age 15 years and older, area of paved roads per capita, and number of family health services people per capita led to increases in the incidence of the infectious diseases. The increase in two social determinants, public green areas per capita and number of public transportation vehicles per 10000 people, led to a reduction in the incidence of infectious diseases.

\section{Table 5: The results of the two-way FE analysis}




\begin{tabular}{|c|c|c|c|c|c|}
\hline & $\beta$ & $S E$ & $t$ & $p$ & $95 \% \mathrm{Cl}$ \\
\hline$x_{1}$ & -0.45 & 0.33 & -1.36 & 0.20 & -1.16 \\
\hline$x_{2}$ & -0.75 & 0.45 & -1.68 & 0.12 & -1.72 \\
\hline$x_{3}$ & -0.66 & 4.38 & -0.15 & 0.88 & -10.07 \\
\hline$x_{4}$ & -52.57 & 64.97 & -0.81 & 0.43 & -191.92 \\
\hline$X_{5}$ & 0.22 & 2.21 & 0.10 & 0.92 & -4.52 \\
\hline$x_{6}$ & -3.56 & 4.12 & -0.86 & 0.40 & -12.39 \\
\hline$x_{7}$ & 5.16 & 1.73 & 2.98 & $0.01^{\star \star}$ & 1.45 \\
\hline$x_{8}$ & 2.23 & 1.68 & 1.33 & 0.21 & -1.37 \\
\hline$X_{9}$ & 4.53 & 9.02 & 0.50 & 0.62 & -14.82 \\
\hline $\mathrm{X}_{10}$ & 3.96 & 3.06 & 1.29 & 0.22 & -2.61 \\
\hline $\mathrm{X}_{11}$ & -8.14 & 1.49 & -5.47 & $0.00 * * *$ & -11.34 \\
\hline $\mathrm{X}_{12}$ & 50.26 & 121.13 & 0.41 & 0.68 & -209.53 \\
\hline$X_{13}$ & 3.88 & 7.57 & 0.51 & 0.62 & -12.35 \\
\hline$X_{14}$ & 85.97 & 59.42 & 1.45 & 0.17 & -41.47 \\
\hline $\mathrm{X}_{15}$ & -5.47 & 1.99 & -2.75 & $0.02 *$ & -9.74 \\
\hline$X_{16}$ & 6.86 & 1.41 & 4.86 & $0.00 * \star \star$ & 3.83 \\
\hline$x_{17}$ & 0.76 & 0.36 & 2.10 & 0.06 & -0.02 \\
\hline $\mathrm{X}_{18}$ & 7.61 & 22.07 & 0.34 & 0.74 & -39.73 \\
\hline $\mathrm{X}_{19}$ & -6.89 & 3.58 & -1.92 & 0.08 & -14.58 \\
\hline$x_{20}$ & 0.71 & 0.41 & 1.71 & 0.11 & -0.18 \\
\hline$x_{21}$ & 7.90 & 1.29 & 6.12 & $0.00 * \star \star$ & 5.13 \\
\hline _cons & 31.07 & 136.87 & 0.23 & 0.82 & -262.50 \\
\hline \multicolumn{6}{|c|}{$F_{(35,14)}=500.23$} \\
\hline \multicolumn{6}{|c|}{$p=0.0000^{\star \star \star \star}$} \\
\hline$R^{2}=0$. & & & & & \\
\hline
\end{tabular}




\section{${ }^{\star} p<0.05, * \star p<0.01, * \star \star * 0<0.001$}

\section{Discussion}

We reported the variation in the average overall yearly incidence of Class A and B notifiable infectious diseases in China from 2004 to 2018, which gradually declined since SARS. This indicated that we had made some achievements in infectious disease control and prevention. The four infectious diseases with the highest incidence during this period were hepatitis, tuberculosis, syphilis and bacterial and amoebic dysentery. Trends in the incidence of the four infectious diseases varied. The incidence of dysentery, which was among the three most infectious diseases before 2008, decreased substantially and was replaced by syphilis. Globally, tuberculosis is one of three main infectious diseases [14], and patients with tuberculosis are mainly refugees from the Middle East, eastern Europe, and Africa [15]. The fluctuation of changes gradually decreased in the yearly incidence of all infectious diseases, including the four major diseases. We also reported differences between seven regions, and the three regions with the highest incidence during this period were Northwest China, South China and Central China. Therefore, we need to pay more attention to these areas. We can improve the skills of people in infectious disease control and prevention by promoting a system of infectious disease control and prevention, educating people from these regions to strengthen their awareness, knowledge and abilities to control and prevent infectious disease, consolidating information system to improve the skills of supervisors in infectious disease control and in inspecting the laboratories to facilitate disease control and management [16], promoting a communication system between health departments and other related government departments to improve the efficiency of communication and speed of emergency responses, and perfecting talent cultivation and incentive mechanisms to reduce talent drainage from the system of infectious disease control and prevention.

The current economic development and the structure of society contributed to the spread of infectious diseases [17]. In the past 30 years, the incidence of Class B notifiable infectious diseases has been influenced by the growth of the GDP in China [18]. We found that the social determinants of health in each region, such as social factors, economic factors, demographic factors and health factors, were related to the significant differences in the incidence of the Class $A$ and $B$ notifiable infectious diseases in various regions. The World Health Organization (WHO) established the Commission on Social Determinants of Health (CSDH) in 2005, which supported each country or region in discovering and addressing the social determinants that contribute to diseases and health inequalities and to encourage research in areas of hygiene and health. The government and academic experts have focused on the social determinants of health and built better social conditions for people, especially vulnerable groups, all over the world, according to the CSDH report. People's health is decisively affected by social and environmental conditions [19]. In South Asia, poverty, food insecurity, illiteracy, lack of health awareness and social stigma were social determinants and formed the foundation for the control and prevention of the further spread of infectious diseases, especially tuberculosis and AIDS [20]. 
We found that the percentage of the illiterate population in the total population of people age 15 years and older can significantly impact the incidence of notifiable Class A and B infectious diseases, and a higher proportion of individuals with illiteracy led to a higher incidence of infectious diseases. People's health literacy is vital, with educated people able to accept health programs better than people with illiteracy [21]. Therefore, improvements to health literacy is a precondition for raising the level of education for all. In China, the rate of health literacy of infectious diseases was 15.85\% [22] in 2008 and $23.15 \%$ in 2020 , according to information released by the $\mathrm{NHC}$, which is a slight increase despite tremendous efforts made for more than 10 years. In 2020, the illiteracy rate was less than $4 \%$, and it had been more than $80 \%$ during the 1950 s in China. We can organize the propagation of education about infectious disease control and prevention during the campaign to wipe out illiteracy. We can also improve hygiene and health literacy through new media and internet platforms, such as WeChat, by publishing information on infectious diseases. According to a report on the Development Status of the Internet Industry and Forecast of Development Trends, internet penetration rose to 67\% in June 2020 in China, and $40.6 \%$ of cyber users had searched for information about health online [23].

In areas with high density, there was a higher incidence of infectious diseases [24] and rapid spread. Specifically, in cities with high density, infectious diseases spread faster. The transmission characteristics of infectious diseases in cities and provinces are different because of some distinct factors, including the total population, population density and GDP; therefore, metropolises should take more stringent measures to control the spread of infectious diseases in China [25]. We found that the level of public facilities in cities had a significant impact on the incidence of infectious diseases. Larger public green areas per capita was associated with a lower incidence of infectious diseases, indicating that the urban environment had a large influence on infectious diseases. Two other factors caused a lower incidence of infectious diseases, the number of public transportation vehicles per 10000 people and area of paved roads per capita, indicating that there was a lower incidence of infectious disease in areas with more convenient public transportation and higher geographical accessibility to health care [26]. Therefore, it may be helpful to reduce the incidence of infectious diseases by making the urban environment increasingly better and raising geographical accessibility to health care.

In addition, we discovered that the number of family health service people per capita also influenced the incidence of infectious diseases. However, there is currently no fixed cooperative relationship between family physicians and centers for disease control and prevention (CDC) in China [27]. In some other countries, family physicians have made great contributions to the efforts for identifying infectious diseases in the community. In Canada, physicians have a legislated responsibility to report suspected or confirmed cases of infectious disease that are on the list of diseases that must be reported to public health authorities [38]. A study suggested that Hungarian family physicians consider reporting infection and suspicion cases was not only a simple obligation but also a professional task [29]. Family physicians' obligation to report is the keystone for proper surveillance of infectious diseases. Therefore, incorporation of family physicians into the CDC system is necessary, as then, we can educate them about the rules of the reporting system [30] and provide information about infectious diseases to spread the knowledge and consciousness of prophylaxis to the masses. 
In conclusion, China has made great progress in the control and prevention of Class A and B notifiable infectious diseases since the SARS outbreak. The trend in the incidence of infectious diseases has decreased since 2004. Hepatitis, tuberculosis, tuberculosis, syphilis and bacterial and amoebic dysentery have the highest yearly incidence, and their incidence has gradually stabilized. The difference in the incidence of infectious diseases was statistically significant between 2004 and 2009 and 2010 to 2018, and it was also statistically significant between the seven regions of China. Some social determinants were found to influence the incidence of infectious diseases. We should continue to decrease the proportion of people with illiteracy in the population, improve the level of health literacy in all populations, especially among people with illiteracy, increase public facilities in cities to ameliorate contributing factors in the urban living environment, increase accessibility to health care by geographical region, and acknowledge that family physicians play important roles in the control and prevention of infectious diseases.

\section{Abbreviations}

GEE: Generalized Estimation Equation

SARS: Severe Acute Respiratory Syndrome

NHC: National Health Commission of the People's Republic China

PLS: Pooled Regression model

FE : Fixed Effects model

RE : Random Effects model

LM test: Lagrangian Multiplier test

GDP: Gross Domestic Product

WHO: World Health Organization

CSDH: Commission on Social Determinants of Health

AIDS: Acquired Immune Deficiency Syndrome

CDC: Center for Disease Control

\section{Declarations}

\section{Ethics approval and consent to participate}

Not applicable. 


\section{Consent for publication}

Not applicable.

\section{Availability of data and materials}

The datasets generated and analysed during the current study are available in the [China Statistical Yearbook] repository, [http://www.stats.gov.cn/english/Statisticaldata/AnnualData/] and [China Health Statistics Yearbook] repository.

\section{Competing interests}

The authors declare that they have no competing interests.

\section{Funding}

This research is supported by a triennial plan of action reinforcing the public health system in Shanghai from 2020 to 2022.(GWV-11)

\section{Authors' contributions}

Zhang $\mathrm{C}$ designed this study and analyzed the results, then drafted the manuscript. Wang $\mathrm{H}$ interpreted the results, and edited the manuscript. Jin $\mathrm{C}$ reviewed the manuscript.

\section{Acknowledgements}

Not applicable.

\section{References}

1. Coronavirus disease (COVID-19) pandemic. https://www.who.int/emergencies/diseases/novelcoronavirus-2019. Accessed 16 Apr 2021.

2. The Global Risks Report 2021, 16th ed. Damage and disparity: Structural fissures exacerbated by the crisis threaten to make the recovery deeply uneven: Fractured Future: World Economic Forum;2021.https://reports.weforum.org/global-risks-report-2021/? doing_wp_cron=1612032827.8358941078186035156250. Accessed 16 Apr 2021.

3. The Global Risks Report 2021, 16th ed. Global risks perceptions: Executive Summary: World Economic Forum;2021. https://reports.weforum.org/global-risks-report-2021/? doing_wp_cron=1612032827.8358941078186035156250. Accessed 16 Apr 2021.

4. National Health Commission of the People's Republic of China. Timeline of China releasing information on COVID-19 and advancing international cooperation. http://en.nhc.gov.cn/202004/06/c_78861_3.htm. Accessed 16 Apr 2021. 
5. Zhang L, Wilson DP. Trends in Notifiable Infectious Diseases in China: Implications for Surveillance and Population Health Policy. PLoS ONE. 2012;7(2); doi:10.1371/journal.pone.0031076.

6. National Health Commission of the People's Republic of China. Law of the People's Republic of China on Prevention and Treatment of Infectious Diseases. http://en.nhc.gov.cn/201903/05/c_74526.htm. Accessed 16 Apr 2021.

7. Zhu B, Fu Y, Liu J, et al. Spatial distribution of 12 category B notifiable infectious diseases in China: A retrospective study. PLoS ONE. 2018;13(4); doi:10.1371/journal.pone.0195568.

8. Jiang Y, Dou X, Yan C, et al. Epidemiological characteristics and trends of notifiable infectious diseases in China from 1986 to 2016. JoGH. 2020;10(2);doi:10.7189/jogh.10.020803.

9. Huda TM, Tahsina T, Arifeen SEl, et al. The importance of intersectoral factors in promoting equityoriented universal health coverage: a multilevel analysis of social determinants affecting neonatal infant and under-five mortality in Bangladesh. Glob Health Action. 2016;9;doi:10.3402/gha.v9.29741.

10. Hilal FA, Herrero MB, Maciel EMGdS, et al. Social determinants of pulmonary tuberculosis in Argentina. Rev. bras. epidemiol. 2019;22;doi:10.1590/1980-549720190003.

11. Du Z, Zhang W, Hao Y. [Distribution patterns of the main respiratory infectious diseases in China and their associated socio-economic factors]. Zhonghuajibingkongzhizazhi. 2016 Jan;20(1):5-8. Chinese.

12. Qiang Chen. [Advanced Econometrics and Stata application]. 2th ed. Beijing: Higher Education Press; 2014. Chinese.

13. Breusch TS, Pagan AR. A simple test for heteroscedasticity and random coefficient variation. Econometrica. 1979;47(5):1287-94.

14. Yang S, Wu J, Ding C, et al. Epidemiological features of and changes in incidence of infectious diseases in China in the first decade after the SARS outbreak: an observational trend study.

15. Lancet Infect Dis. 2017;17(7):716-25.

16. Ritz N, Brinkmann F, Garcia BS, et al. Tuberculosis in young refugees. The Lancet. 2015;386(10012):2475-6.

17. Zhang X, Hou F, Li X, et al. Study of surveillance data for class B notifiable disease in China from 2005 to 2014. International Journal of Infectious Diseases. 2016;48:7-13.

18. Shortanov RA. Research on the Multisectoral Impact of Infectious Diseases on the Economy. JPRI. 2020;32(27):47-57.

19. Zhang T, Yin F, Zhou T, et al. Multivariate time series analysis on the dynamic relationship between Class B notifiable diseases and gross domestic product (GDP) in China. Sci Rep 6. 2016;(29);doi: 10.1038/s41598-016-0020-5.

20. Irwin A, Scali E. Action on the social determinants of health: a historical perspective. Global Public Health. 2007;2(3):235-56.

21. Bishwajit G, Ide S, Ghosh S. Social Determinants of Infectious Diseases in South Asia. International Scholarly Research Notices.2014;doi:10.1155/2014/135243. 
22. R. Beaglehole. International trends in coronary heart disease mortality, morbidity, and risk factors. Eidemiologic Reviews,1990;12:1-15.

23. Wang P, Mao Q, Tao M, et al. [Survey on the status of health literacy of Chinese residents in 2008]. Zhongguojiankangjiaoyu. 2010;26(4):243-6. Chinese

24. Qiu Y, Ren W, Liu Y, et al. Online health information in a rural residential population in Zhejiang Province, China: a cross-sectional study. BMJ Open. 2019;9(5);doi:10.1136/bmjopen-2018-026202.

25. Anser MK, Islam T, Khan MA, et al. Identifying the Potential Causes, Consequences, and Prevention of Communicable Diseases (Including COVID-19). BioMed Research International. 2020; doi:10.1155/2020/8894006.

26. Niu X, Yue Y, Zhou X, et al. How Urban Factors Affect the Spatiotemporal Distribution of Infectious Diseases in Addition to Intercity Population Movement in China. J. Geo-Inf. 2020,9(11), 615; https://doi.org/10.3390/ijgi9110615.

27. Hierink F, Okiro EA, Flahault A, et al. The winding road to health: A systematic scoping review on the effect of geographical accessibility to health care on infectious diseases in low- and middle-income countries. PLoS ONE. 2020;16(1);doi:10.1371/journal.pone.0244921.

28. Ren Y, Ma L. [Emphasize the role of community prevention and control of family physicians in public health emergencies]. Zhonghuaquankeyixue. 2020;18(10):1615-8. Chinese.

29. Summers A, Hu J, Berger L. Important role of family physicians in reporting communicable diseases. Can Fam Physician. 2018;64:742-3.

30. Vraukó K, Jancsó Z, Kalabay L, et al. An appraisal: how notifiable infectious diseases are reported by Hungarian family physicians. BMC Infect Dis. 2018;18(1);doi:10.1186/s12879-018-2948-5. 30.TóthVraukó K, Vitrai J, Mucsi Gy, et al. [Attitude of family physicians for reporting infectious diseases]. Orv. Hetil. 2014;155(31):1228-35. Hungarian.

\section{Figures}




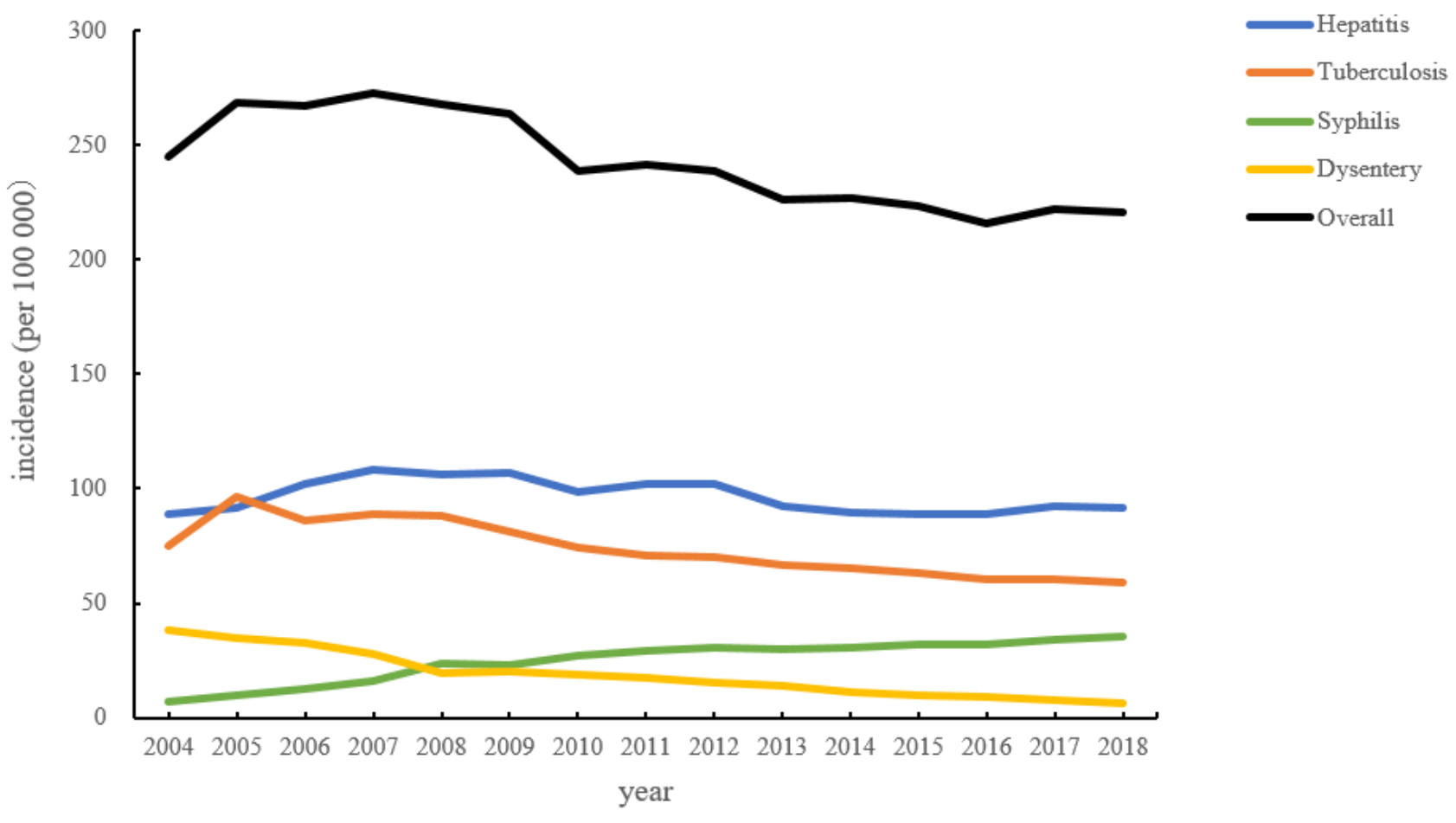

Figure 1

The incidence of overall infectious disease and the four main infectious diseases from 2004 to 2018 


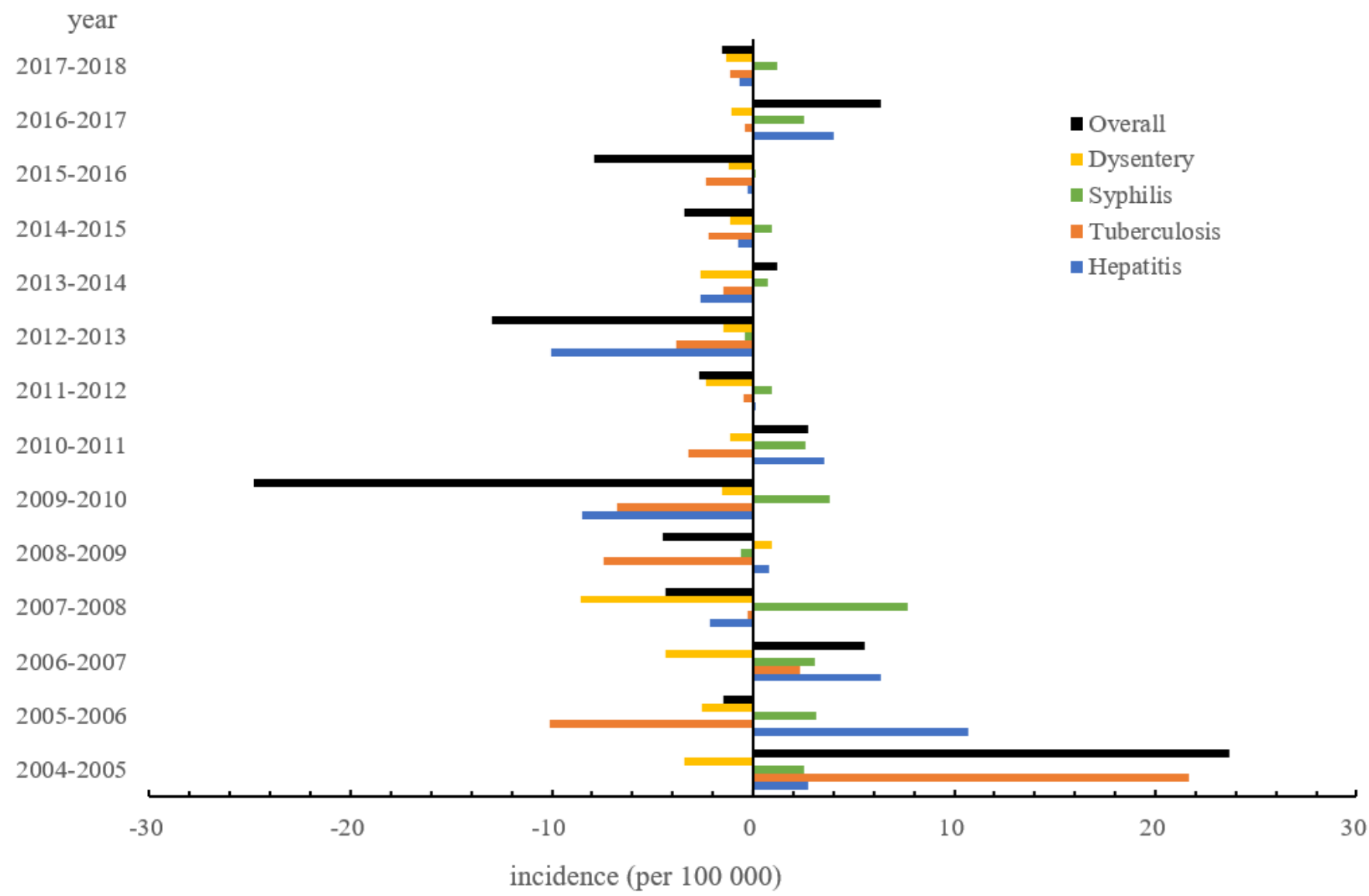

Figure 2

The variation in the incidence of overall infectious disease and the four main infectious diseases from 2004 to 2018 

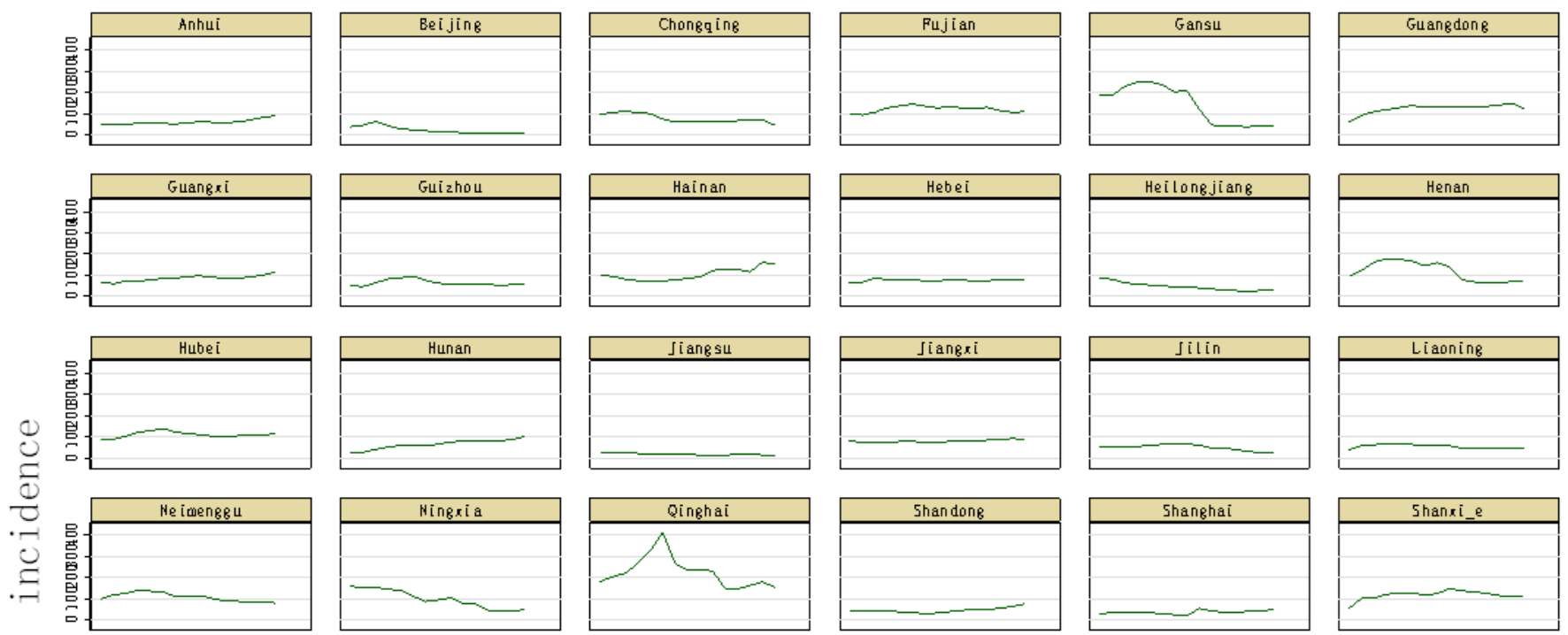

Ningxia

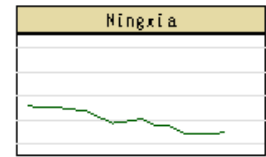

Shanxi_.
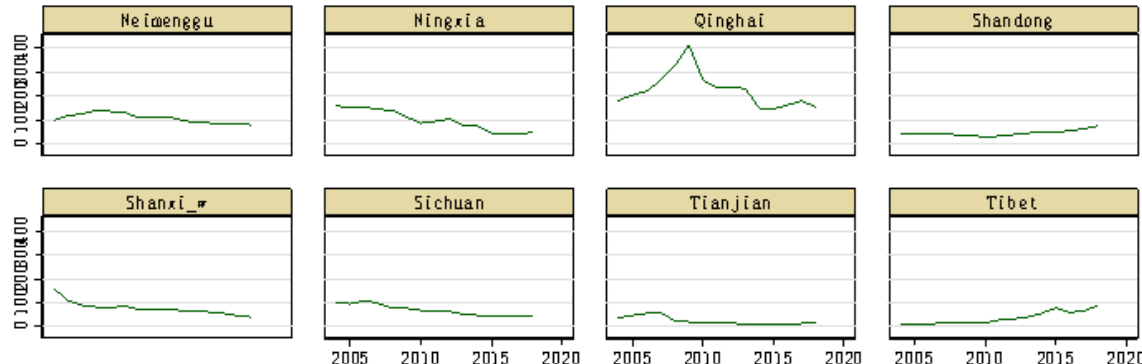

Tian jian
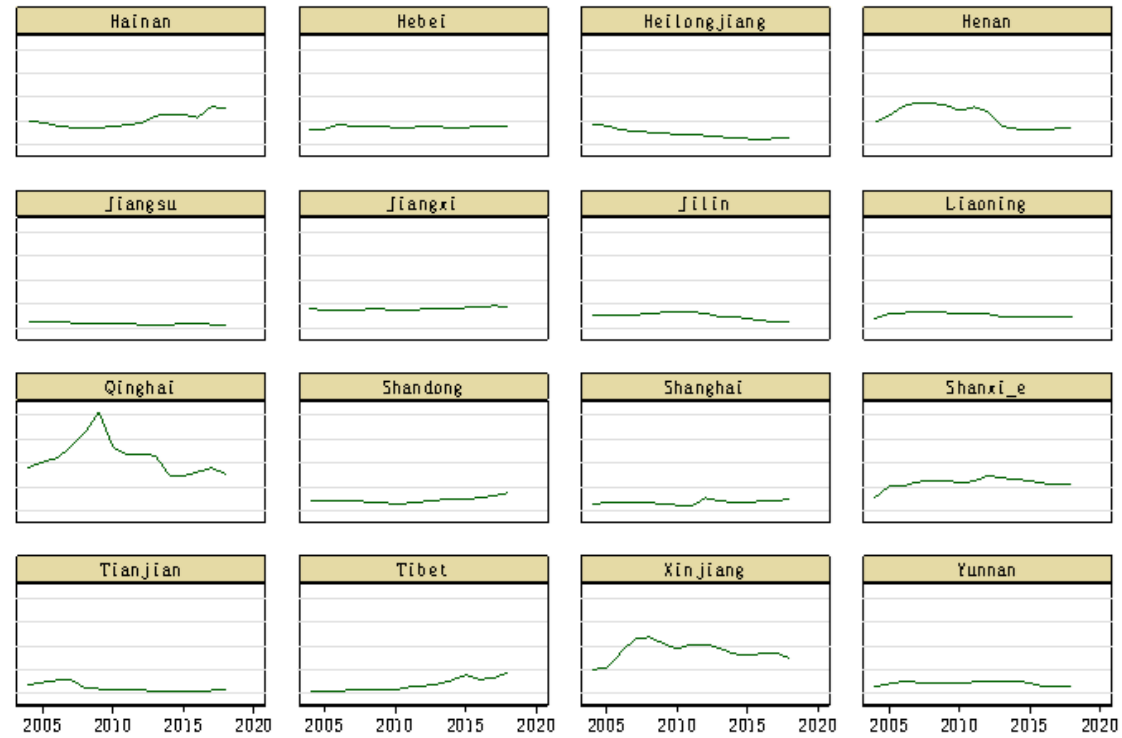

Shanghai
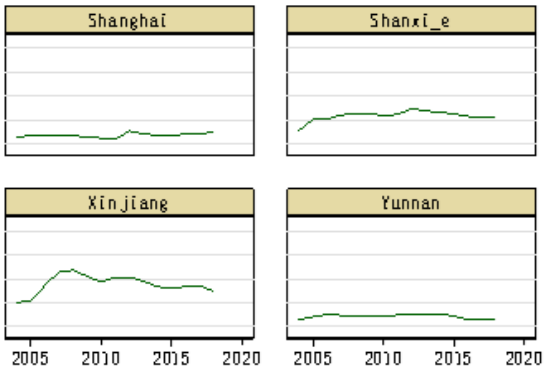

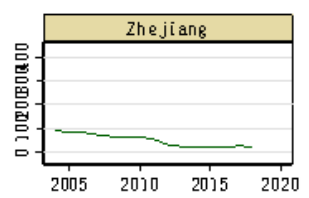

Graphs by province

year

\section{Figure 3}

The trends of the incidence of Class A and B notifiable infectious diseases in 31 provinces from 2004 to 2018 